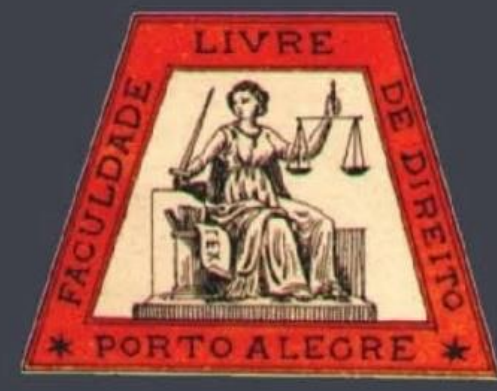

\title{
Capacidade civil, interdição e curatela: As implicações jurídicas da Lei n. 13.146/2015 para a pessoa com deficiência mental
}

Legal Capacity, Interdiction and Curatorship: The Legal Implications of the Statute $n^{\circ} 13.146 / 2015$ for Persons with Mental Disabilities

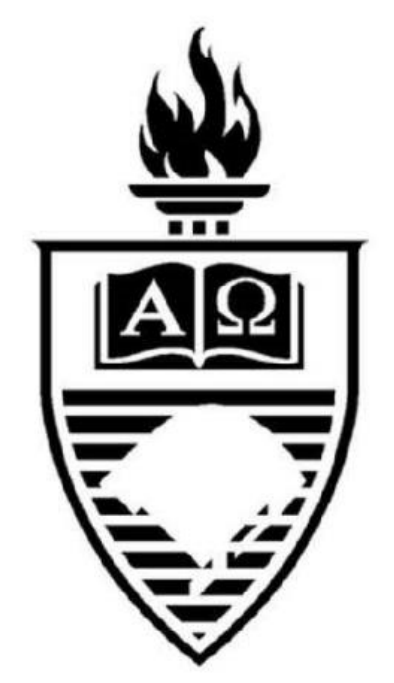

\section{Iara Antunes Souza}

Universidade Federal de Ouro Preto

Michelle Danielle Cândida Silva

Universidade Federal de Ouro Preto

\section{UFRGS}




\title{
Capacidade civil, interdição e curatela: As implicações jurídicas da Lei n. 13.146/2015 para a pessoa com deficiência mental
}

\author{
Legal Capacity, Interdiction and Curatorship: The Legal Implications of the Statute $n^{\circ} 13.146 / 2015$ \\ for Persons with Mental Disabilities
}

Iara Antunes Souza*

Michelle Danielle Cândida Silva**

\begin{abstract}
REFERÊNCIA Alegre, n. 37, p. 291-310, dez. 2017.
\end{abstract}

SOUZA, Iara Antunes; SILVA, Michelle Danielle Cândida. Capacidade civil, interdição e curatela: As implicações jurídicas da Lei n. 13.146/2015 para a pessoa com deficiência mental. Revista da Faculdade de Direito da UFRGS, Porto

\begin{abstract}
The paper discusses the legal treatment conferred to the Incapacity Theory under Brazilian law, over time, and to its related institutes, namely, to the interdiction and curator. It approaches the new systematics adopted in the ambit of the capacity and of the incapacity regime by the Statute on Persons with Disabilities, especially, it discusses the situation of persons who have disabilities due to mental health. It deals, in addition, with the questions of procedural order that marked the validity of the Statute and the 2015 Civil Procedure Code in the field of curatorship and interdiction.
\end{abstract}

\section{KEYWORDS}

Incapacities Theory. Statute on Persons with Disabilities. Human Dignity. Interdiction. Curatorship.
Teoria das Incapacidades. Estatuto da Pessoa com Deficiência. Dignidade Humana. Interdição. Curatela.

\section{SUMÁRIO}

Introdução. 1. A Teoria da Capacidade e das Incapacidades no direito brasileiro. 1.1 Como a Teoria das (In)Capacidades foi tratada pelo Direito brasileiro ao longo do tempo? 1.2. A revisitação da Teoria das Incapacidades trazida pelo Estatuto da Pessoa com Deficiência. 2. A curatela e o regime da interdição no ordenamento jurídico brasileiro e no estrangeiro. 2.1. A interdição e a curatela no direito alemão e o francês. 2.2. A curatela e a interdição a partir do Estatuto da Pessoa com Deficiência. 2.3. O modelo da curatela conjunta ou compartilhada. 3. A concretização do Estatuto da Pessoa com Deficiência à luz do Código de Processo Civil de 2015. Conclusão. Referências.

\section{INTRODUÇÃO}

O Código Civil vigente, Lei n. 10.406, de 10 de janeiro de 2002, regulamenta a Teoria das Incapacidades nos artigos $3^{\circ}$ e $4^{\circ}$. O Estatuto da

\footnotetext{
* Doutora e Mestra em Direito Privado pela PUC Minas. Especialista em Direito Processual e Direito Civil. Pesquisadora do Centro de Estudos em Biodireito - CEBID. Professora da Graduação e da Pós-Graduação do Departamento de Direito da Universidade Federal de Ouro Preto. Chefe do DEDIR/EDTM/UFOP. Advogada do NAJOP/UFOP. Vice Coordenadora do Comitê de Ética em Pesquisa da UFOP. Membro do IBDFAM MG e da comissão de Direito de Família da OAB MG.

*** Bacharel em Direito pela Universidade Federal de Ouro Preto.
} 
Pessoa com Deficiência - EDP, Lei n. 13.146, de 06 de julho de 2015, implantou um microssistema legal de proteção e promoção da pessoa com deficiência e promoveu sensíveis alterações nos dispositivos, revisitando o conceito de capacidade civil.

Antes da entrada em vigor do EDP, a incapacidade civil era determinada seguindo dois critérios: pela ausência ou redução de discernimento em função da idade e pela ausência ou redução do discernimento em razão da saúde mental. A partir de 2016, em face das mudanças empreendidas pelo Estatuto da Pessoa com Deficiência, para o ordenamento jurídico brasileiro, apenas os menores de dezesseis anos são absolutamente incapazes, tendo o legislador excluído do rol de pessoas absolutamente incapazes as pessoas "com enfermidade ou deficiência mental" e deslocado para o rol dos relativamente incapazes "os que, por causa transitória, não puderem exprimir sua vontade" $\left(\operatorname{art} .4^{\mathrm{ol}}\right)$.

As mudanças introduzidas pelo microssistema legal refletiram na situação jurídica das pessoas que possuem o discernimento reduzido em virtude de deficiência mental, bem como nos institutos erigidos para tutelar a pessoa considerada pelo ordenamento jurídico como incapaz, quais sejam: a interdição e a curatela, uma vez que as normatizações estabelecidas, até então no Código Civil, quanto ao processo de interdição, foram revogadas expressamente pelo EPD, que, além disso, conferiu à curatela o caráter de medida protetiva excepcional dirigida à proteção e dignificação da pessoa com deficiência.

Especialmente acerca do instituto da interdição destacam-se, ainda, questões de Direito

\footnotetext{
${ }^{1}$ Art. $4^{\circ}$ São incapazes, relativamente a certos atos ou à maneira de os exercer:

I - os maiores de dezesseis e menores de dezoito anos;

II - os ébrios habituais e os viciados em tóxico;

III - aqueles que, por causa transitória ou permanente, não puderem exprimir sua vontade;
}

Processual, uma vez que o novo Código de Processo Civil, que entrou em vigor dia 17 de março de 2016, regulamentou a interdição no âmbito processual, na contramão do Estatuto da Pessoa com Deficiência, que revogou dispositivos do Código Civil acerca do tema.

Diante desse panorama, objetiva-se apresentar quais as implicações jurídicas da Lei n. 13.146/2015 - EDP - na capacidade civil, interdição e curatela para a pessoa com deficiência mental.

Inicialmente, apresenta-se um estudo acerca da Capacidade e da Teoria das Incapacidades no ordenamento jurídico brasileiro, no que tange as pessoas com deficiência mental e, especialmente, o novo panorama jurídico posteriormente ao Estatuto da Pessoa com Deficiência. Após, aborda-se as mudanças operadas na interdição e no instituto da curatela, a partir da entrada em vigor do EPD e as questões de Direito Processual que circundam, nesse aspecto, a concretização do microssistema legal a partir da entrada em vigor do Código de Processo Civil de 2015, Lei n. $13.105 / 2015$.

\section{A TEORIA DA CAPACIDADE E DAS INCAPACIDADES NO DIREITO BRASILEIRO}

Segundo os civilistas Cristiano Chaves e Nelson Rosenvald (2015, p. 271), a capacidade civil confere às pessoas naturais a aptidão genérica para "adquirir direitos e assumir pessoalmente deveres" na esfera jurídica, trata-se, pois, de instituto jurídico que qualifica os sujeitos como "potenciais titulares de relações jurídicas". Classifica-se doutrinariamente em: capacidade de

IV - os pródigos.

Parágrafo único. A capacidade dos indígenas será regulada por legislação especial. (BRASIL, 2002). 
direito - de aquisição ou gozo; e capacidade de fato - de exercício.

A capacidade de direito é conferida a toda pessoa natural, razão pela qual se consubstancia na própria personalidade, também reconhecida a toda e qualquer pessoa, e concretiza-se a na possibilidade de ser sujeito de direitos. A capacidade de fato, por sua vez, diz respeito à “aptidão para praticar pessoalmente, por si mesmo, os atos da vida civil" (FARIAS, ROSENVALD, 2015, p. 271-272).

Diz-se que o sujeito possui capacidade jurídica plena quando, no plano fático, pode exercer, por si só, os direitos e deveres de que é titular. Em outras palavras, possui capacidade jurídica plena o sujeito que, além da capacidade direito, detém capacidade de fato.

A capacidade de direito é absoluta, assim como a personalidade, qualidade, contudo, que não se estende à capacidade de fato, sobre a qual incide à Teoria das Incapacidades em razão da possibilidade de sua gradação. Assim, dada a possibilidade de reconhecimento de graus variados de capacidade de fato, para o ordenamento jurídico, existem pessoas absolutamente incapazes e pessoas relativamente incapazes (FARIAS, ROSENVALD, 2015, p. 272).

No plano jurídico, a regra é a capacidade, sendo a incapacidade exceção; assim, consideram-se incapazes as pessoas que não possuem, por si só, o necessário discernimento para a prática dos atos da vida civil. Absolutamente incapazes são as pessoas "que não possuem qualquer capacidade de agir, sendo irrelevante, do ponto de vista jurídico, a sua manifestação de vontade" (FARIAS, ROSENVALD, 2015, p. 276), necessitam, pois, da representação legal de um terceiro. Relativamente incapazes são aquelas que

2Acerca de tal denominação, Iara Antunes de Souza (2016, p. 183) assinala que "coadunava com a classificação da loucura na época - Idade Moderna - antes de sua ligação possuem o discernimento para a prática dos atos da vida civil reduzido, e, nessa condição, exigem auxílio de terceiro para exercê-los, de modo que sua vontade não é ignorada (FIÚZA, 2014, p. 159).

Tendo em conta que este trabalho cuida especificamente das consequências da Teoria das Incapacidades para as pessoas com deficiência mental, cumpre-se realizar breve escorço histórico da capacidade civil e o regime das incapacidades no direito pátrio no que tange às pessoas tidas como incapazes em razão da saúde mental.

\subsection{Como a Teoria das (In)Capacidades foi tratada pelo Direito brasileiro ao longo do tempo?}

O Brasil, na qualidade de colônia de Portugal, e, posteriormente, como Império, sujeitou-se às normas ditadas pelo seu colonizador. Assim, vigoraram, nessas épocas, no país, as Ordenações Afonsinas (1446-1521), Manuelinas (1521-1569) e Filipinas (1603-1830), estas últimas vigentes mesmo após a independência, em 1822.

Sob a égide das Ordenações Afonsinas, a maioridade civil era alcançada aos 25 anos de idade, de modo que aos menores era determinado um tutor e aos maiores designado um curador. Os encargos eram exercidos pelos pais ou pela esposa e, na ausência deles, atribuíam-se tais funções ao ascendente paterno, ao irmão maior de idade ou a terceiro estranho, designado pelo juiz, que ficava responsável pela pessoa mesmo nos intervalos de lucidez. Entretanto, neste caso, a pessoa considerada sem juízo - nomeada como furioso ${ }^{2}$ - poderia administrar seus bens (SOUZA, 2016, p. 183).

com a Medicina e mudança de nomenclatura para transtornos mentais". 
Durante a vigência das Ordenações Manuelinas (1521-1569), não foram editadas normas que dispensassem tratamento específico para a curatela. Havia, contudo, a previsão de representação processual ${ }^{3}$ dos menores de idade por um curador até que atingissem a maioridade civil - 25 (vinte e cinco) anos de idade (SOUZA, 2016, p. 183).

Nas Ordenações Filipinas (1603-1830) previu-se a nomeação de um tutor aos meninos menores de 14 (quatorze) anos e às meninas menores de 12 (doze) anos, quando órfãos. Ultrapassada tal idade, e até os 25 (vinte e cinco) anos, eram nomeados curadores. Aos considerados mentecaptos e pródigos, maiores de 25 (vinte e cinco) anos, também eram dados curadores. O tratamento conferido, nesta época, em muito se assemelhava ao concedido ao sandeu, nas Ordenações Manuelinas (SOUZA, 2016, p. 183).

O Brasil tornou-se independente de Portugal, em 1822, entretanto, as Ordenações Filipinas permaneceram vigentes. Promulgada a Constituição de 1824, essa determinou a organização de um Código Civil, que só foi editado em 1916. Conforme assevera Iara Antunes de Souza (2016, p. 185), até a edição do Código Beviláqua "foram editadas várias normas esparsas que modificavam o teor das ordenações".

Destaca Caio Mário da Silva Pereira (2000, p. 54), ao discorrer sobre a história da Codificação Brasileira, que, antes da elaboração do Código Civil de 1916, foi a Consolidação das Leis Civis, obra elaborada por Augusto Teixeira de Freitas, em 1858, um dos marcos jurídicos pátrio. Segundo o jurista, a produção de tal normatização

\footnotetext{
3 Tratava-se de curadoria "semelhante à curadoria processual” (SOUZA, 2016, p. 183).

4Segundo Caio Mário (2000, p. 161-162), “aliada à ideia de personalidade, a ordem jurídica reconhece ao indivíduo a capacidade para aquisição de direito e para exercê-los por si mesmo, diretamente, ou por intermédio, ou com assistência de outrem. [...] Como toda pessoa tem personalidade, tem também a faculdade abstrata de gozar de seus direitos."
}

foi determinada pelo Governo Imperial e serviu de medida preliminar para produção de um Código Civil nacional, que, conforme determinava a Constituição Imperial, deveria ser elaborado o mais rápido possível.

$\mathrm{Na}$ Consolidação das Leis Civis, os loucos de todo gênero e os pródigos recebiam tratamento equiparados aos menores e a curatela era dispensada à pessoa com loucura que pudesse fazer mal. Incumbia ao curador a responsabilidade pelo patrimônio do curatelado e o encargo de providenciar o tratamento médico necessário (SOUZA, 2016, p. 186-187).

Em $1^{\circ}$ de janeiro de 1917 , entrou em vigor o Código Civil de 1916. O novo diploma civil cuidou de regulamentar a capacidade civil, que foi dividida em capacidade de direito e capacidade de fato. A primeira era conferida a todas as pessoas naturais, tendo o legislador adotado um conceito de capacidade de direito coincidente com o de personalidade ${ }^{4}$. Por sua vez, a capacidade de fato determinava a aptidão da pessoa de exercer, por si só, os direitos que titularizava e estava ligada à idade e ao estado de saúde mental da pessoa. A capacidade de fato e de exercício - capacidade plena - presumia-se adquirida aos 21 (vinte e um) anos de idade (MONTEIRO, 1990, p. 61).

A ausência total ou parcial da capacidade de fato era regulada pelo regime das incapacidades, que conferia proteção jurídica às pessoas consideradas absolutamente incapazes e relativamente incapazes.

Extrai-se da leitura dos dispositivos que disciplinavam o regime das incapacidades, arts. $5^{\circ}$ e $6^{\circ 5}$ do Código Civil de 1916, que a idade e a loucura - "loucos de todo gênero", ditavam a

5 Art. 5. São absolutamente incapazes de exercer pessoalmente os atos da vida civil:

I. Os menores de dezesseis anos.

II. Os loucos de todo o gênero.

III. Os surdos-mudos, que não puderem exprimir a sua vontade. IV. Os ausentes, declarados tais por ato do juiz. (BRASIL, 1916)

Art. $6^{\circ}$ São incapazes relativamente a certos atos (art. 147, $\left.\mathrm{n}^{\mathrm{o}} \mathrm{I}\right)$, ou à maneira de os exercer: 
(in)capacidade da pessoa em exprimir ou não sua vontade e figuravam como critérios para aferir a incapacidade absoluta. A incapacidade relativa era determinada pela idade, pela caracterização da prodigalidade - dilapidação do patrimônio de forma descontrolada - e pela qualidade de silvícola, considerados na legislação, como não civilizados quando não inseridos na sociedade civil. Aqui, como já exposto, importa o tratamento conferido aos denominados "loucos de todo gênero"6.

O Código Civil de 1916 considerava que a pessoa acometida pela loucura era sempre absolutamente incapaz para realizar os atos da vida civil, desconsiderando, assim, o denominado lucida intervala (MIRANDA, 1999, p.266).

Assevera Iara Antunes de Souza (2016, p. 189) que, embora fosse a loucura tratada pelo ordenamento pátrio como causa de incapacidade absoluta, a sua positivação como tal não encontrava amparo nas ciências médicas da época, visto que já existiam "tratamentos e possibilidades de expressão de autonomia do chamado louco pelo Código".

A Lei n. 10.406, de 10 de janeiro de 2002, revogou o Diploma Civil de 1916 e instituiu o novo Código Civil. O novo ordenamento jurídico civil, contudo, não abraçou a realidade delineada no âmbito das relações sociais, a partir da promulgação da Constituição da República de 1988, que implantou o Estado Democrático de

I - Os maiores de 16 e os menores de 21 anos (arts. 154 e 156).

II - Os pródigos.

III - Os silvícolas".

Parágrafo único. Os silvícolas ficarão sujeitos ao regime tutelar, estabelecido em leis e regulamentos especiais, o qual cessará à medida que se forem adaptando à civilização do País . (BRASIL, 1916)

Obs.: O art. $6^{\circ}$ foi alterado pela Lei n. 4.121, de 1962 que exclui do rol de pessoas consideradas relativamente incapazes as mulheres casadas.

6 Segundo Iara Antunes de Souza (2016, p. 188-189), o termo "loucos de todo gênero" foi herdado do Código Criminal do Império, e utilizado até entrada em vigor do Código Civil de 2002, tendo a psiquiatria constatado que a natureza estritamente discriminatória da expressão já havia
Direito no Brasil. A pessoa humana ascendeu à qualidade de ser dotado de dignidade humana, e a sua promoção foi consagrada como fundamento da República Federativa. No entanto, o tratamento conferido às pessoas consideradas incapazes ocupou-se mais uma vez de questões patrimoniais.

O Código Civil de 2002 repetiu as disposições acerca da aquisição de personalidade jurídica. Da mesma forma, permaneceu a fragmentação da capacidade civil em capacidade de direito - inerente a toda e qualquer pessoa natural, a partir do nascimento com vida (arts. $1^{\circ}$ e $2^{\circ}$ ), caracterizando-se como a aptidão para contrair direitos e deveres na ordem jurídica, e a capacidade de fato consubstanciada na possibilidade de exercer, por si só, os atos da vida civil.

No que tange ao regime das incapazes, para o Código Civil de 2002, antes das mudanças empreendidas pelo EPD, eram absolutamente incapazes as pessoas sem qualquer discernimento para a prática dos atos da vida civil, que deviam ser representadas perante a ordem jurídica. Os relativamente incapazes, a seu turno, eram os que possuíam capacidade de expressar a sua vontade e de praticar parcialmente os atos da vida civil, necessitando apenas de alguém que os auxiliassem (FARIAS; ROSENVALD, 2015, p. 276- 279). Os artigos $3^{\circ}$ e $4^{\circ} 7$ cuidaram de disciplinar a incapacidade civil.

sido abandonada em outros países. No mesmo sentido são as lições do mestre Washington Monteira de Barros (1990, p. 61) que assinala que a impropriedade da expressão era reconhecida pela unanimidade dos comentadores.

7 Art. $3^{\circ}$ São absolutamente incapazes de exercer pessoalmente os atos da vida civil:

I - os menores de 16 (dezesseis) anos;

II - os que, por enfermidade ou deficiência mental, não tiverem o necessário discernimento para a prática desses atos;

III - os que, mesmo por causa transitória, não puderem exprimir sua vontade. (BRASIL, 2002).

Art. $4^{\circ}$ São incapazes, relativamente a certos atos, ou à maneira de os exercer: I - os maiores de dezesseis e menores de dezoito anos; 
Vê-se que o Código Civil de 2002 tratou a incapacidade da pessoa sob dois critérios: em razão da idade e da saúde mental. A partir do primeiro critério, determinou-se que os maiores de 18 anos são absolutamente capazes, os menores de 16 anos absolutamente incapazes e os maiores de 16 anos e menores de 18 anos relativamente incapazes. No que diz respeito à saúde mental, consideram-se absolutamente incapazes as pessoas que não tenham qualquer discernimento em razão do transtorno mental, e relativamente incapazes as pessoas que tenham o discernimento parcialmente reduzido em virtude dele. Exclui-se do rol de pessoas consideradas absolutamente incapazes o surdo-mudo e os ausentes. Os pródigos passaram a ser classificados como relativamente incapazes e a capacidade dos silvícolas regulamentada em lei especial.

Especialmente em relação à situação das pessoas incapazes em razão da saúde mental, no qual se debruça este estudo, verifica-se que o texto renunciou a nomenclatura "loucos de todo gênero" e passou a referir-se à enfermidade ou deficiência mental que retira ou reduza o necessário discernimento para a prática dos atos da vida civil. Manteve, pois, o Código Civil o transtorno mental como causa de incapacidade total ou relativa.

A previsão da incapacidade absoluta em razão da saúde mental sem gradação, no entanto, acabava por negar a realidade de que o transtorno mental, embora pudesse retirar o discernimento para a prática de alguns atos da vida civil, não importava na ausência total para outros atos da vida. Assim, conforme assinala Iara Antunes de Souza, a Teoria das Incapacidades distanciava-se das realidades jurídicas, médicas e psicológicas e obstava a concretização da dignidade humana:

II - os ébrios habituais, os viciados em tóxicos, e os que, por deficiência mental, tenham o discernimento reduzido;

III - os excepcionais, sem desenvolvimento mental completo; IV - os pródigos.
A teoria das incapacidades que era esculpida nos artigos $3^{\circ}$ e $4^{\circ}$ do Código Civil representava uma posição legislativa estática e positiva, que gerava distanciamento entre a teoria e as práticas jurídica, médica e psicológica, em muito não solucionando os casos concretos e desumanizando o Direito. Ou seja, não respeitava a proteção e promoção da dignidade da pessoa humana exigida pela Constituição da República de 1988 (SOUZA, 2016, p. 33).

Nesse contexto, conforme as lições de Cristiano Chaves e Nelson Rosenvald (2015, p.285), a decisão judicial que reconhecia a incapacidade absoluta e decretava a interdição feria direitos fundamentais da pessoa humana, como a liberdade, a intimidade, a cidadania entre outras, razão pela qual não poderia a mera existência de "patologia mental" ser considerada para a decretação da interdição, exigindo, assim que, o reconhecimento da incapacidade, atentasse-se mais a necessidade do incapaz do que as meras questões patrimoniais de que era o incapaz titular.

A proteção conferida pelo ordenamento jurídico à pessoa com transtorno mental sofreu profunda alteração a partir do Estatuto da Pessoa com Deficiência como se passa a analisar.

\subsection{A revisitação da Teoria das Incapacidades trazida pelo Estatuto da Pessoa com Deficiência}

A Constituição da República de 1988 positivou como fundamento do Estado Democrático de Direito a dignidade da pessoa humana (artigo $1^{\circ}, \mathrm{III}$ ); este princípio passou a ocupar o vértice do ordenamento jurídico brasileiro, exigindo que o legislador concretizasse, no plano normativo, a promoção de direitos e garantias fundamentais do homem.

Não obstante ter sido instituído em 2002, o Código Civil - Lei n. 10.406, de 10 de janeiro de

Parágrafo único. A capacidade dos índios será regulada por legislação especial. (BRASIL, 2002). 
2002 -, como mencionado, mostrou-se em descompasso com o primado da dignidade humana, especialmente em relação às pessoas com algum tipo de transtorno mental. Nesse contexto, a fim de efetivar as exigências constitucionais, promovendo a proteção e a promoção inclusiva da pessoa com deficiência, no dia 06 de julho de 2015, foi sancionada a Lei n. 13.146/2015, que instituiu o Estatuto da Pessoa com Deficiência.

A partir da entrada em vigor da novel legislação, em 03 de janeiro de 2016 - 180 (cento e oitenta) dias após a publicação oficial da lei - a pessoa com deficiência passou a ser tutelada por um microssistema jurídico em sintonia com os ditames constitucionais que norteiam o Estado Democrático de Direito.

O Estatuto da Pessoa com Deficiência concretiza a Convenção Internacional sobre os Direitos das Pessoas com Deficiência, incorporada ao direito interno através do Decreto 6.949, de 25 de agosto de 2009, com status de norma constitucional, uma vez que sua aprovação observou o procedimento disposto no $\$ 3^{\circ}$ do art. $5^{\circ 8}$ da Carta Constitucional de 1988.

Segundo o art. $2^{\circ}$ EPD, considera-se com deficiência a pessoa "que tem impedimento de longo prazo de natureza física, mental, intelectual ou sensorial, o qual, em interação com uma ou mais barreiras, pode obstruir sua participação plena e efetiva na sociedade em igualdade de condições com as demais pessoas." (BRASIL, 2015).

Conceituada a deficiência, cuidou o Estatuto de estabelecer, na esteira do disposto na Convenção de New York (art. 12), que a

$8[\ldots] \S 3^{\circ}$ Os tratados e convenções internacionais sobre direitos humanos que forem aprovados, em cada Casa do Congresso Nacional, em dois turnos, por três quintos dos votos dos respectivos membros, serão equivalentes às emendas constitucionais. (BRASIL, 1988)

9 Art. 84. A pessoa com deficiência tem assegurado o direito ao exercício de sua capacidade legal em igualdade de condições com as demais pessoas. deficiência não suprimi a capacidade, sendo o deficiente detentor de capacidade legal, capacidade está que deve ser exercida em igualdade de condições com as demais pessoas (art. $84^{9}$ ) e que, nas lições de Paulo Lôbo (2015), é mais ampla que a capacidade civil.

Com o fim de concretizar as novas disposições estatutárias, vários dispositivos do Código Civil de 2002 referentes à capacidade civil foram alterados e até mesmo revogados pelo microssistema legal, o que culminou em "grandes mudanças estruturais e funcionais na antiga teoria das incapacidades" (TARTUCE, 2015a).

$\mathrm{O}$ art. $3^{\circ}$ do Diploma Civil, que dispõe acerca dos considerados absolutamente incapazes, teve todos os seus incisos revogados, tendo o seu caput mantido como única hipótese de incapacidade absoluta a do menor de 16 (dezesseis) anos.

$\mathrm{O}$ art. $4^{\circ}$, a seu turno, que disciplina a incapacidade relativa, também foi alterado. Permaneceu a previsão dos menores púberes entre 16 (dezesseis) anos completos e 18 (dezoito) anos incompletos, no inciso I; o inciso II, por sua vez, eliminou a referência à deficiência mental, constando, agora, tão somente "os ébrios habituais e os viciados em tóxico"; o inciso III, que continha "o excepcional sem desenvolvimento mental completo", passou a cuidar apenas das pessoas que, "por causa transitória ou permanente, não possam exprimir a sua vontade"; e, no inciso IV, permaneceu a previsão da incapacidade relativa do pródigo.

No que tange à situação jurídica da pessoa considerada incapaz em razão da saúde mental, como assinala Iara Antunes de Souza (2016, p.

§ 1ํ Quando necessário, a pessoa com deficiência será submetida à curatela, conforme a lei.

$\S 2^{2}$ É É facultado à pessoa com deficiência a adoção de processo de tomada de decisão apoiada.

$\S 3$ o A definição de curatela de pessoa com deficiência constitui medida protetiva extraordinária, proporcional às necessidades e às circunstâncias de cada caso, e durará o menor tempo possível. (BRASIL, 2015). 
32-33), o microssistema legal abandona a enfermidade ou doença como critério de incapacidade, anunciando que a deficiência não gera, por si só, e nem é causa automática da configuração da incapacidade. Na verdade, nem mesmo a deficiência, por si só, é causa de incapacidade.

Eventualmente, poderá a pessoa com algum transtorno ou deficiência mental, que lhe retire o discernimento totalmente ou parcialmente, ter a sua capacidade limitada, sendo submetida, de forma excepcional e como medida protetiva, ao regime da curatela. Tal medida, porém, não importa na supressão da capacidade do indivíduo de se autodeterminar, em especial na esfera existencial.

Nessa esteira, verifica-se, que a partir do Estatuto da Pessoa com Deficiência, o fato do sujeito possuir algum transtorno ou deficiência de natureza mental, seja qual for a natureza, não o insere instantaneamente no rol de incapazes.

\section{A CURATELA E O REGIME DA INTERDIÇÃO NO ORDENAMENTO JURÍDICO BRASILEIRO E NO ESTRANGEIRO}

Como mencionado, a capacidade de fato admite variações e gradações, assim, para o ordenamento jurídico, além de plenamente capazes, as pessoas podem ser absolutamente ou relativamente incapazes em função da ausência total ou parcial do necessário discernimento para a prática de todos os atos da vida.

As pessoas consideradas absolutamente incapazes são aquelas, como dito, que não têm qualquer discernimento para agir de acordo com sua autodeterminação, e, por isso, sua manifestação de vontade não é considerada juridicamente. Uma vez que a incapacidade absoluta impossibilita as pessoas de exercerem, por si só, os atos da vida civil, elas precisam ser representadas legalmente por um terceiro, que praticará os atos em seu nome, sendo os atos praticados diretamente por pessoa absolutamente incapaz nulos de pleno (inciso I, do art.166 do Código Civil). A seu turno, os relativamente incapazes possuem capacidade de expressarem sua vontade ainda que com assistência de outrem, de modo que os atos praticados sem a presença do assistente legal são passíveis de anulação (FARIAS; ROSENVALD, 2015, p.276-277).

Para conferir tutela às pessoas que são absolutamente incapazes de exercer os atos da vida civil, embora maiores de idade, o ordenamento jurídico instituiu a curatela. Nas palavras de Clóvis Beviláqua (1934, p.448), curatela é "o encargo público conferido por lei, a alguém, para dirigir a pessoa e administrar os bens dos maiores, que por si só não possam fazê-lo". Segundo Cristiano Chaves e Nelson Rosenvald (2011, p. 927), "é mecanismo de proteção de uma pessoa maior, mas, também reputada incapaz, com esteio em uma das causas previstas no Código Civil".

Há que se ressaltar que a curatela não se confunde com a tutela, instituto jurídico destinado à proteção da criança ou adolescente fora do poder familiar em virtude da morte, ausência ou destituição de seus pais (FARIAS; ROSENVALD, 2011, p. 972).

A instituição da curatela, tanto no passado como atualmente, ocorre por meio de um procedimento denominado interdição. Segundo Pontes de Miranda (2000, p. 374), a interdição “é ato do poder público pelo qual se declara ou se retira (= desconstitui) a capacidade negocial de alguém".

Tradicionalmente, a decretação da interdição e, por consequência, a atribuição da curatela a uma pessoa por determinação legal, na prática jurídica, suprimia da pessoa maior incapaz a possibilidade de praticar atos em situações existenciais, negando-lhe, deste modo, espaços de autonomia para construção de uma vida digna. $\mathrm{Na}$ verdade, a interdição configurava verdadeira 
morte civil, razão pela qual despontava no instituto o seu caráter patrimonialista, cuja finalidade principal era a "administração do patrimônio do incapaz e estabilidade jurídica no tráfego de riquezas do que propriamente alguma preocupação de recuperação com o interditando" (BROCHADO; RODRIGUES, 2010, p.23-24).

$\mathrm{O}$ instituto, entretanto, ganhou novos contornos a partir do Estatuto da Pessoa com Deficiência que, ao reconhecer que a deficiência não afasta a capacidade legal - capacidade mais extensa que a capacidade civil em geral (LÔBO, 2015), determina que a curatela seja aplicada quando necessário e na qualidade de medida protetiva extraordinária, nos termos do seu art. $84^{10}$.

\section{Analisando}

historicamente

as

normatizações brasileiras, observa-se que às pessoas consideradas incapazes em razão da saúde mental a curatela era medida que se impunha.

Como reportado, as Ordenações Afonsinas previam a nomeação de um tutor ou curador para o filho defassisado ou pródigo. Nas Ordenações Manuelinas, não houve a previsão de curatela para os loucos, falava-se, porém, na representação processual dos menores até os 25 (vinte e cinco) anos de idade por um curador. As Ordenações Filipinas, por sua vez, determinavam a nomeação de curador aos que tinham 14 (quatorze) anos, se homens, e 12 (doze) anos, se mulheres, e 25 (vinte e cinco) anos aos que fossem órfãos, e aos mentecaptos ou pródigos maiores de 25 anos (SOUZA, 2016, p. 183-184).

\footnotetext{
10 Art. 84. A pessoa com deficiência tem assegurado o direito ao exercício de sua capacidade legal em igualdade de condições com as demais pessoas.

$\S 1$ 1o Quando necessário, a pessoa com deficiência será submetida à curatela, conforme a lei.

$\S 2$ o É facultado à pessoa com deficiência a adoção de processo de tomada de decisão apoiada.

$\S 30$ A definição de curatela de pessoa com deficiência constitui medida protetiva extraordinária, proporcional às necessidades e às circunstâncias de cada caso, e durará o menor tempo possível.
}

A Consolidação das Leis Civis, elaborada por Teixeira de Freitas, após a independência do Brasil, em 1822, equiparava "os loucos de todo gênero" aos menores. Estavam sujeitos à curatela, conforme assevera Iara Antunes de Souza (2016, p. 186-187), as pessoas com loucura que pudessem fazer mal e eram legitimadas para assumi-la a esposa, os pais, os avós maternos e paternos, o filho varão e maior de 21 (vinte e um) anos, o irmão maior e os parentes, maternos ou paternos, mais próximos. $\mathrm{Na}$ ausência desses, o juiz poderia nomear qualquer estranho (art. 312). Com exceção da esposa, as pessoas nomeadas não podiam escusar-se de exercer a curatela. (SOUZA, 2016, p. 185-187).

O Código Civil de 1916, em seu artigo $446^{11}$, previa que as pessoas consideradas "loucos de todo o gênero" deveriam ser representadas civilmente por um curador. $\mathrm{O}$ procedimento de interdição encontrava previsão nos arts. 447 a 453 do mesmo Código e com regulamentação, inicialmente, no Código de Processo Civil de 1939, entre os arts. 606 a 620; a partir da instituição do Código de Processo Civil de 1973, o procedimento foi disciplinado nos arts. 1.177 a 1.186.

Em linhas gerais, eram legitimados para promover a interdição do louco o pai, a mãe ou tutor, o cônjuge, ou algum parente próximo, e o Ministério Público, que poderia requer a interdição nos casos de loucura furiosa (inciso I, do art. 448, do CPC de 1939). Posteriormente, a partir do Código de Processo Civil de 1973, no caso de anomalia psíquica (inciso I, art. 1.178, do

$\S 4$ o Os curadores são obrigados a prestar, anualmente, contas de sua administração ao juiz, apresentando o balanço do respectivo ano. (BRASIL, 2015)

${ }^{11}$ Art. 446. Estão sujeitos à curatela:

I. Os loucos de todo o gênero (arts. 448, n. I, 450 e 457).

II. Os surdos-mudos, sem educação que os habilite a enunciar precisamente a sua vontade (arts. 451 e 456).

III. Os pródigos (arts. 459 e 461). (BRASIL, 1916) 
CPC de 1973) e na ausência, inércia ou incapacidade dos demais legitimados o Parquet podia requerê-la.

A decretação da interdição pressupunha a constatação da incapacidade, que era aferida pelo juiz ao examinar pessoalmente o interditando e pelo parecer de outros profissionais (art. $450 \mathrm{e}$ art. 1.181 do CPC de 1973). Segundo Pontes de Miranda (2000, p. 379), a interdição dos loucos, ainda que retirasse do indivíduo o exercício pessoal de seus direitos, era benefício da lei.

O Código Civil de 2002, em seu art. $1.767^{12}$, ainda que tenha abandonado a expressão "louco de todo gênero", estabeleceu, a partir do regime de incapacidades adotado, que estavam sujeitos à curatela e, consequentemente, à interdição as pessoas maiores com "enfermidade", "deficiência mental" e "excepcional sem desenvolvimento mental completo".

Além disso, o Código estabelecia a possibilidade de recolhimento das pessoas consideradas incapazes por deficiência mental, sem o discernimento necessário para os atos da vida, e os excepcionais a estabelecimentos "adequados"13.

Assim, embora tenha o novo Código Civil sido instituído sob os ditames da Constituição da República de 1988, a curatela continuou assumindo a feição patrimonialista do Código Civil 1916, negando ao incapaz a possibilidade de exercer com autonomia as situações existenciais, que lhe eram inerentes, e promovendo a sua exclusão social.

\subsection{A interdição e a curatela no direito alemão e o francês}

\footnotetext{
${ }^{12}$ Art. 1.767. Estão sujeitos a curatela:

I - aqueles que, por enfermidade ou deficiência mental, não tiverem o necessário discernimento para os atos da vida civil;

II - aqueles que, por outra causa duradoura, não puderem exprimir a sua vontade; III - os deficientes mentais, os ébrios habituais e os viciados em tóxicos;
}

No ordenamento jurídico francês, o instituto da curatela assume natureza protetiva intermediária. Dirige-se às pessoas que não conseguem "agir por si mesmas, necessitando de aconselhamento ou controle dos atos da vida civil” (VIEIRA, 2004, p.11).

A curatelle encontra-se prevista no art. 440 do Código Civil Francês e a sua determinação não impunha necessariamente um procedimento de interdição, não o sendo assim designado no ordenamento francês atual. Pressupõe, contudo, uma aplicação proporcional "ao grau de alteração das faculdades da pessoa" (SOUZA, 2016. p. 168167).

A medida protetiva é destinada as pessoas maiores de 18 (dezoito) anos que, de acordo com averiguação médica, não podem exprimir sua vontade em virtude de "comprometimento das faculdades mentais ou físicas" (SOUZA, 2016, p. 169), e por isso não possuem, total ou parcialmente, condições de gerir sua vida e seus bens.

$\mathrm{Na}$ sistemática jurídica atual alemã, a proteção conferida ao incapaz traduz-se na “autorização judicial específica para diferentes atos relacionados à vida civil e atos médicos da pessoa com transtorno mental" (SOUZA, 2016, p. 179).

No ordenamento alemão, a interdição, prevista inicialmente pelo BGB - como ficou conhecido o Código Civil Alemão - foi abolida do ordenamento em 1992, em uma das reformas pela qual passou, e, em seu lugar, introduziu-se o instituto da Orientação e Cuidado, que concede maior autonomia à pessoa considerada incapaz em razão de transtorno ou deficiência mental, na

IV - os excepcionais sem completo desenvolvimento mental; (BRASIL, 2002).

${ }^{13}$ Art. 1.777. Os interditos referidos nos incisos I, III e IV do art. 1.767 serão recolhidos em estabelecimentos adequados, quando não se adaptarem ao convívio doméstico." (BRASIL, 2002). 
medida em que se constitui em uma autorização judicial para a prática específica de determinados atos da vida civil e atos médicos (SOUZA, 2016, p. 179).

O modelo de curatela alemã não se estende, portanto, a priori, a todos os atos da vida civil. Nas lições de Iara Antunes de Souza (2016, p. 179), a medida é restrita aos casos de necessidade da pessoa com deficiência mental e não pressupõe a decretação da incapacidade:

Graduam-se os atos e decisões, não se estendendo a curatela a qualquer ato da vida do indivíduo. Em suma, por não existir prévia interdição, não há uma determinação de incapacidade, logo, a pessoa com deficiência ou doença mental mantém sua capacidade e é orientada quando e somente quando não apresenta discernimento.

Ainda que explanado em linhas gerais, notase que o instituto estabelecido no ordenamento jurídico alemão guarda mais sintonia com o tratamento protetivo que deve ser dedicado à pessoa incapaz em razão da saúde mental, sendo proporcional às necessidades de cada um. Da mesma forma, diga-se da curatelle francesa que, precipuamente, tem em conta os graus de diminuição do discernimento, proporcionado pelo transtorno ou deficiência mental, no momento de sua determinação.

O modelo brasileiro em muito se distanciou desses ordenamentos, em que pesem os Códigos Civis de 1916 e 2002 terem sido inspirados nos grandes Códigos europeus. O Estatuto da Pessoa com Deficiência, contudo, ao alterar as disposições concernentes à curatela e disciplinála, promoveu certa aproximação no tratamento conferido a tais institutos.

\subsection{A curatela e a interdição a partir do Estatuto da Pessoa com Deficiência}

\footnotetext{
${ }^{14}$ Art. 1.767. Estão sujeitos a curatela:

I - aqueles que, por causa transitória ou permanente, não puderem exprimir sua vontade;
}

Com a entrada em vigor do Estatuto da Pessoa com Deficiência, a todas as pessoas com deficiência mental, de qualquer natureza, é reconhecido o direito de exercer a sua capacidade legal em igualdade de condições com as demais pessoas (caput, art. 84). Reconhece-se que a deficiência, por si só, não retira o discernimento da pessoa. Assim, ante a nova perspectiva de capacidade, cuidou o microssistema legal de dedicar novo tratamento jurídico à curatela em seu texto.

Nos ditames do EPD, a partir de agora, a curatela é medida excepcional, extraordinária, a ser adotada apenas e na proporção das necessidades do curatelado, durando o menor tempo possível $\left(\$ 1^{\circ}\right.$ do art. 84$)$. Em outras palavras, a instituição da curatela pressupõe a avaliação das circunstâncias incapacitantes em cada caso, afastando-se, de plano, a limitação absoluta da capacidade do sujeito. Segundo Paulo Lôbo (2015), o novo modelo de curatela caracteriza-se como medida de efetiva proteção "e não de interdição de exercício de direito".

Visando concretizar as novas disposições, o Estatuto revogou expressamente os artigos do Código Civil de 2002 que disciplinavam a matéria. Assim, nos termos do art. 123 da novel legislação, foram revogados os incisos II e IV do art. $1.767^{14}$ que estabeleciam que estavam sujeitos à curatela "aqueles que, por outra causa duradoura, não puderem exprimir a sua vontade" e "os excepcionais sem completo desenvolvimento mental".

Deste modo, a partir de então, estão sujeitos à curatela, em caráter excepcional, as pessoas que, por causa transitória ou permanente, não puderem exprimir sua vontade. Além disso, dispôs o EPD expressamente que a curatela restringir-se-á apenas às relações de natureza patrimonial de que

II - (Revogado);

III - os ébrios habituais e os viciados em tóxico; IV (Revogado);

V - os pródigos. (BRASIL, 2002). 
o curatelado for titular, afastando a sua incidência da esfera regida pela autonomia privada e que tangencia as situações existenciais da pessoa humana.

Nos termos do art. 85 do Estatuto da Pessoa com Deficiência, a curatela não atinge o direito ao próprio corpo, à sexualidade, ao matrimônio, à privacidade, à educação, à saúde, ao trabalho e ao voto.

Assim, hodiernamente, não cabe interpretar o instituto como medida que esteriliza a pessoa incapaz em razão da saúde mental para exercer, por si mesma, a sua plena autonomia existencial.

As novas disposições referentes à curatela, inseridas pelo EPD no Código Civil de 2002, foram objeto de alteração pelo Código de Processo Civil de 2015, vindo à lume a discussão acerca da existência ou não da interdição atualmente. Não será aborda neste momento o atropelo legislativo. Dedica-se um capítulo para tal fim.

O Estatuto da Pessoa com Deficiência, além de atribuir à curatela natureza excepcionalíssima, regulamentou a possibilidade de ser o encargo compartilhado por dois curadores, como exposto a seguir.

\subsection{O modelo da curatela conjunta ou compartilhada}

A curatela compartilhada é a inovação trazida pelo Estatuto da Pessoa com Deficiência ao Código Civil de 2002. Prevista em seu art. $1.775^{15}$, tal modalidade de curatela permite ao juiz nomear mais de curador à pessoa com deficiência.

Trata-se de medida que objetiva, precipuamente, conservar o bom relacionamento familiar do curatelado, privilegiando, por consequência, a qualidade de vida dele, uma vez que mais de um curador desempenharia mais de uma função no exercício da curatela (COELHO, 2016, p. 27).

Para Maria Berenice Dias (2016, p. 676677), a curatela compartilhada poderá ser concedida aos pais do curatelado e a quaisquer outras pessoas, sejam elas parentes ou não do curatelado, podendo esse também "indicar uma ou mais pessoas para o exercício da curatela". Cada curador poderá receber incumbências específicas (LÔBO, 2015).

Segundo a jurista Thaís Câmara Maia Fernandes Coelho (2016, p. 28), esse é o caso da curatela fracionada, também possível no ordenamento jurídico brasileiro. Nesta espécie de curatela, o magistrado, ao nomear mais de curador, fixa quais as responsabilidades, podendo, por exemplo, atribuir a um o exercício da administração patrimonial do curatelado e ao outro a responsabilidade pelas providências médicas de que necessite a parte (COELHO, 2016, p. 28).

Trata-se, dessa forma, de espécie de curatela que objetiva maximizar a proteção conferida à pessoa do curatelado e, ao mesmo tempo, estabelecer equilíbrio na atribuição do encargo ao curador.

\section{A CONCRETIZAÇÃO DO ESTATUTO DA PESSOA COM DEFICIÊNCIA À LUZ DO CÓDIGO DE PROCESSO CIVIL DE 2015}

Aludiu-se, ao longo deste texto, que o Estatuto da Pessoa com Deficiência trouxe novas disposições acerca dos direitos e liberdade fundamentais das pessoas com deficiência, concebendo novos contornos ao conceito de capacidade civil até então adotado pelo ordenamento jurídico.

Dentre as alterações promovidas pelo Estatuto no contexto da promoção e inclusão da

\footnotetext{
${ }^{15}$ Art. 1.775-A. Na nomeação de curador para a pessoa com deficiência, o juiz poderá estabelecer curatela compartilhada a mais de uma pessoa. (BRASIL, 2002).
} 
pessoa com deficiência de natureza mental, destaca-se o caráter extraordinário atribuído à curatela, que, a partir de agora, é medida protetiva aplicada de forma excepcional e proporcional às circunstâncias de cada caso, devendo durar o menor tempo possível.

A fim de concretizar suas disposições, o EPD, Lei n. 13.146, de 06 de julho de 2015, em vigor desde janeiro de 2016, promoveu significativas mudanças no Código Civil de 2002 na parte em que esse disciplinava o procedimento de interdição. Ou seja, o Estatuto não alterou o Código de Processo Civil de 1973, ainda em vigor quando da edição do microssistema legal, mas sim as disposições procedimentais da interdição estabelecidas no Código Civil.

O Código de Processo Civil de 2015, Lei n. 13.105, de 16 de março de 2015, entrou em vigor, em março de 2016, pouco tempo após o Estatuto da Pessoa com Deficiência, e revogou expressamente diversos dispositivos do Código Civil, inclusive os que cuidavam do procedimento da interdição e haviam sido objeto de alteração pelo EPD. Tais revogações, conforme aponta Paulo Lôbo (2015) teriam ocorrido, supostamente, porque dispunham matéria de ordem processual e não de direito material.

Como já discutido, a curatela, “é mecanismo de proteção de uma pessoa maior, mas, também reputada incapaz, com esteio em uma das causas previstas no Código Civil". (CHAVES; FARIAS, 2011, p. 927) e que, a datar da entrada em vigor do Estatuto da Pessoa com Deficiência, é medida de caráter excepcional, proporcional às necessidades do curatelado, devendo durar o menor tempo possível. A interdição, por sua vez, é o procedimento através do qual se constituí a curatela.

O Estatuto da Pessoa com Deficiência, ao mesmo tempo em que alterou as disposições referentes à curatela, extirpou do Código Civil a expressão interdição. Assim, de acordo com a alteração do EPD, o art. 1.768 passou a discriminar, em seu caput, que "o processo que define os termos da curatela deve ser promovido [...]". O Código de Processo Civil, entretanto, revogou tal dispositivo e os artigos alterados pelo EPD que versavam sobre o procedimento adotado para a curatela, avocando para si a disciplina da interdição entre os seus arts. 747 e 758.

Nesse contexto, a entrada em vigor do Diploma Processual Civil e a revogação de dispositivos alterados pelo EPD representou verdadeiro atropelo legislativo, despontando na doutrina discussão acerca da existência, ou não da interdição, no ordenamento jurídico brasileiro desde então.

A esse respeito, formaram-se duas correntes: (1) a que compreende que não há mais interdição no direito brasileiro, visto que as pessoas com deficiências não são mais incapazes; e a (2) que entende que as pessoas com deficiência podem ser reconhecidas como incapazes, contudo, a proteção conferida pelo ordenamento, neste caso, será realizada apenas por meio da curatela (SOUZA, 2016, p. 293).

Não obstante o brilhantismo da discussão travada, entende-se que razão assiste à Iara Antunes de Souza (2016, p. 294-295), para quem a interdição é plenamente possível, uma vez que se trata de medida jurídica e judicial por meio da qual o Judiciário verificará, a partir das provas produzidas, a ausência de discernimento para a prática dos atos da vida civil que, eventualmente, poderá ensejar o reconhecimento da incapacidade absoluta ou relativa da pessoa cuja deficiência é de ordem mental:

\footnotetext{
[...] logo, não obstante as alterações do Estatuto da Pessoa com Deficiência, continua vigente no sistema jurídico brasileiro. Entretanto, sua aplicação prática de outrora, como visto no capítulo 3 , deve ser alterada e não pode ser usada mais como meio de segregação e afastamento indiscriminado da capacidade da pessoa, chegando a provocar a morte civil. (SOUZA, 2016, p. 294).
}

Assim, ainda que tenha o EPD alterado a redação do artigo 1.768 do Código Civil, 
suprimindo a expressão "interdição", de tal alteração não decorre a inexistência do procedimento no ordenamento jurídico, até porque a curatela é prevista em situações excepcionais e proporcionais às necessidade da pessoa que a ela se submete. Deve-se, contudo, atentar-se ao fato de que o procedimento não pode culminar no aniquilamento da autonomia existencial do indivíduo perante o seio social.

Atualmente, portanto, é plenamente possível o pedido de interdição, o que, no entanto, se realizado, não ensejará, como outrora, a interdição absoluta da pessoa com deficiência submetida à medida protetiva, uma vez que ela tem reconhecida sua capacidade plena para o exercício de sua autonomia em termos existenciais, sendo objetivo da normatização vigente promover e assegurar a dignidade humana da pessoa com deficiência.

\section{CONCLUSÃO}

Tendo em vista os aspectos abordados, constata-se que, antes da entrada em vigor do Estatuto da Pessoa com Deficiência, a previsão da incapacidade absoluta em razão da saúde mental negava a realidade de que o transtorno mental, embora pudesse retirar o discernimento para a prática de alguns atos da vida civil, não importava a ausência total para outros atos da vida.

O Estatuto da Pessoa com Deficiência, ao efetivar a Convenção de New York, e afastar do rol de incapazes o sujeito que possui algum transtorno mental, seja qual for a natureza, reconheceu que a deficiência, por si só, não retira o discernimento da pessoa; concretizando, no plano normativo, a promoção de direitos e garantias fundamentais do homem para as pessoas com deficiência mental.

Por sua vez, agora, a curatela, como instituto jurídico dedicado à tutela das pessoas maiores incapazes - assim declaradas judicialmente através do processo de interdição apresenta-se como medida excepcional a ser adotada apenas e na proporção das necessidades do curatelado, pelo menor tempo possível e sua determinação pressupõe a avaliação das circunstâncias incapacitantes em cada caso.

Certo é, pois, que eventual declaração de incapacidade e nomeação de curador para $o$ deficiente mental não tem o condão de afastar a autonomia do curatelado de autodeterminar-se como pessoa humana, promovendo, o instituto jurídico, em qualquer caso, o livre desenvolvimento da personalidade humana.

\section{REFERÊNCIAS}

AMARAL, Francisco. Direito civil: introdução. $3^{\mathrm{a}}$ ed. Rio de Janeiro: Renovar, 2006.

BEVILAQUA, Clóvis. Código civil dos Estados Unidos do Brasil, vol.4. 4. ed. Rio de Janeiro: F. Alves, 1934.

BRASIL. Constituição da República Federativa do Brasil de 1988. Disponível em: <http://www.planalto.gov.br/ccivil_03/Constituicao/Constituicao.htm〉. Acesso em: 22 jun. 2017.

. Decreto-lei no. 1.608, de 18 de setembro de 1939. Código de Processo Civil. Disponível em: < http://www.planalto.gov.br/ccivil_03/decreto-lei/1937-1946/Del1608.htm〉. Acesso em: 17 jun. 2017. 
Decreto Legislativo $\mathrm{n}^{\circ}$. 186, de 2008. Aprova o texto da Convenção sobre os Direitos da Pessoa com Deficiência e de seu Protocolo Facultativo, assinados em Nova Iorque, em 30 de março de 2007. Disponível em: <http://www.planalto.gov.br/ccivil_03/Congresso/DLG/DLG-1862008.htm>. Acesso em: 20 de abr. 2017.

Decreto $\mathrm{n}^{\circ} .6 .949$, de 25 de agosto de 2009. Promulga Convenção sobre os Direitos das Pessoas com Deficiência e seu Protocolo Facultativo, assinado em Nova York, em 30 de março de 2007 Disponível em: <http://www.planalto.gov.br/ccivil_03/_ato20072010/2009/decreto/d6949.htm>. Acesso em: 16 jun. 2017.

. Lei no . 3.071, de $1^{\circ}$ de janeiro de 1916. Código Civil dos Estados Unidos do Brasil. Disponível em: <http://www.planalto.gov.br/ccivil_03/leis/L3071.htm>. Acesso em 25 jun. 2017.

. Lei no . 5.869, de 11 de janeiro de 1973. Institui o Código de Processo Civil. Disponível em: < http://www.planalto.gov.br/ccivil_03/leis/L5869.htm >. Acesso em: 22 abr. 2017.

Lei $\mathrm{n}^{\mathrm{o}}$. 10.406, de 10 de janeiro de 2002. Institui o Código Civil. Disponível em: <http://www.planalto.gov.br/ccivil_03/leis/2002/L10406.htm>. Acesso em: 22 jun. 2017.

. Lei no ${ }^{\circ}$ 13.105, de 16 de março de 2015. Institui o Código de Processo Civil. Disponível em: <http://www.planalto.gov.br/ccivil_03/_ato2015-2018/2015/lei/113105.htm> Acesso em: 22 jun. 2017.

. Lei no ${ }^{\circ}$ 13.146, de 06 de julho de 2015. Instituiu a Lei Brasileira de Inclusão da Pessoa com Deficiência (Estatuto da Pessoa com Deficiência). Disponível em: <http://www.planalto.gov.br/ccivil_03/_ato2015-2018/2015/lei/113146.htm >. Acesso em: 02 abr. 2017.

BRAZIL. Constituição Politica do Imperio do Brazil. Constituição Política do Império do Brazil, elaborada por um Conselho de Estado e outorgada pelo Imperador D. Pedro I, em 25.03.1824. Carta de Lei de 25 de Março de 1824. Disponível em: <http://www.planalto.gov.br/ccivil_03/constituicao/constituicao24.htm>. Acesso em 17 jun. 2017.

COELHO, Thais Câmara Maia Fernandes. Autocuratela. Rio de Janeiro: Lumem Juris, 2016.

DEUTSCHLAND. Bürgerliches Gesetzbuch - BGB. Disponível em: <https://www.gesetze-iminternet.de/bgb/>. Acesso em: 05 nov. 2017.

DIAS, Maria Berenice. Manual de direito das famílias. 6ª ed. São Paulo: Revista dos Tribunais, 2010.

. Manual de direito das famílias: de acordo com o novo CPC. 11. ed., rev., atual. e ampl. São Paulo, Revista dos Tribunais, 2016. 
FARIAS, Cristiano Chaves de; ROSENVALD, Nelson. Curso de Direito Civil: parte geral e LINDB. 13. ed. rev., atual e ampl. São Paulo: Atlas, 2015. Juris, 2011.

. Curso de Direito Civil: Direito das Famílias. 3. ed., rev. ampl. e atual. Rio de Janeiro, Lumen .; CUNHA, Rogério Sanches; PINTO, Ronaldo Batista. Estatuto da Pessoa com Deficiência comentado artigo por artigo. 2. rev., ampl. e atual. Salvador: JusPodivm, 2016.

FIUZA, César. Direito civil: curso completo. $1^{\mathrm{a}}$ ed. Belo Horizonte: Del Rey, 2014.

FRANCE. Code civil: Version consolidée au 1 novembre 2017. Disponível em: <https://www.legifrance.gouv.fr/affichCode.do?cidTexte=LEGITEXT000006070721\&dateTexte=20 171211>. Acesso em: 05 nov. 2017.

GUSTIN, Miracy Barbosa de Sousa; Dias, Maria Tereza Fonseca. (Re)pensando a pesquisa jurídica: teoria e prática. $3^{\mathrm{a}}$ ed. Belo Horizonte: Del Rey, 2002.

LÔBO, Paulo Luiz Netto. Com avanços legais, pessoas com deficiência mental não são mais incapazes. Conjur, 2015. Disponível em: <http://www.conjur.com.br/2015-ago-16/processo-familiaravancos-pessoas-deficiencia-mental-nao-sao-incapazes\#author>. Acesso em: 27 abr. 2017.

MIRANDA, Pontes de. Tratado de Direito Privado. V.1. 1 ${ }^{\text {a }}$ ed. Campinas: Booksseller, 1999.

. Tratado de Direito Privado. V.9. 2a ed. Campinas: Booksseller, 2000.

MONTEIRO, Washington de Barros. Curso de Direito Civil. 28. ed. e atual. São Paulo: Saraiva, 1989.

MOUREIRA, Diogo Luna. Os Desafios dos Transtornos Mentais e do Comportamento para o Direito Civil: Dialética do reconhecimento e sofrimento de indeterminação como pressupostos para a reconstrução da Teoria das Incapacidades. 2013. 273f. Tese (Doutorado) - Pontifícia Universidade Católica de Minas Gerais, Programa de Pós-Graduação em Direito, Belo Horizonte. Disponível em:<http://www.biblioteca.pucminas.br/teses/Direito_MoureiraDL2_1.pdf>. Acesso 20 abr. 2017.

PEREIRA, Caio Mário da Silva. Instituições do direito Civil. Rio de Janeiro: Forense, 2000.

PEREIRA, Rodrigo da Cunha. Lei 13.146 acrescenta novo conceito para capacidade civil. Conjur, 2015. Disponível em: <http://www.conjur.com.br/2015-ago-10/processo-familiar-lei-13146acrescenta-conceito-capacidade-civil>. Acesso em: 2 dez. 2015. 
PONTIFÍCIA UNIVERSIDADE CATÓLICA DE MINAS GERAIS. Pró-Reitoria de Graduação. Sistema Integrado de Bibliotecas. Orientações para elaboração de trabalhos científicos: projeto de pesquisa, teses, dissertações, monografias, relatório entre outros trabalhos acadêmicos, conforme a Associação Brasileira de Normas Técnicas (ABNT). 2. Ed. Belo Horizonte: PUC Minas, 2016. Disponível em: <www.pucminas.br/biblioteca>. Acesso em 12 jul. 2017.

PORTUGAL. Ordenações Afonsinas. Disponível em: <http://www1.ci.uc.pt/ihti/proj/afonsinas/pagini.htm>. Acesso em: 05 nov. 2017.

. Ordenações Filipinas. vol. 1-5. Rio de Janeiro: Edição de Cândido Mendes de Almeida, 1870. Disponível em: <http://www1.ci.uc.pt/ihti/proj/filipinas/ordenacoes.htm>. Acesso em: 05 nov. 2017.

Ordenações Manuelinas. Disponível

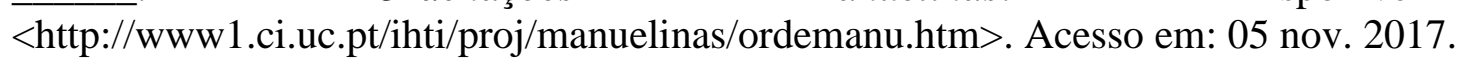

REQUIÃO, Maurício. Compare a incapacidade nos sistemas brasileiro e argentino. Conjur, 2016. Disponível em:<http://www.conjur.com.br/2016-jun-27/direito-civil-atual- compare-incapacidadesistemas-brasileiro-argentino>. Acesso em: 20 jul. 2017.

ROSENVALD, Nelson. A Dignidade e a Curatela. 2015. Disponível em: < https://www.nelsonrosenvald.info/single-post/2015/10/13/A-dignidade-e-a-curatela >. Acesso em: 31 jun. 2017.

ROSENVALD, Nelson. Câmara aprova curatela compartilhada para pessoas com deficiência. 2015. Disponível em: <http://www.nelsonrosenvald.info/\#!Câmara-aprova-curatela-compartilhada-parapessoas-comdeficiência/c21xn/55dcf8770cf21d94cc544ce>. Acesso em: 07 jul. 2017.

\begin{abstract}
Conheça o Estatuto da Pessoa com Deficiência. 2015. Disponível em: <http://www.nelsonrosenvald.info/\#!Conheça-o-Estatuto-da-Pessoa-com-

Deficiência/c21xn/55dd00010cf2c4072861d98d>. Acesso em: 07 de jun. 2017.

Curatela compartilhada para pessoas com deficiência é aprovada pela Câmara. IBDFAM Instituto Brasileiro de Direito de Família (Online). Belo Horizonte, 21 jul. 2015. Disponível em: <http://www.ibdfam.org.br/noticias/5698/Curatela+compartilhada+para+pessoas+com+defici\%C3\% AAncia+\%C3\%A9+aprovada+pela+C\%C3\%A2mara>. Acesso em: 13 jun. 2017.
\end{abstract}

O fim da Interdição - A Biografia não Autorizada de uma Vida. 2015. Disponível em: <http://www.nelsonrosenvald.info/\#!O-Fim-da-Interdição--A-Biografia-não-Autorizada-de-umaVida/c21xn/55e4ca320cf28ffc7eed5e60>. Acesso em: 13 de jun. 2017.

SCHREIBER, Anderson. Tomada de Decisão Apoiada: o que é e qual sua utilidade?. Carta Forense (Online), 2016. Disponível em:< http://www.cartaforense.com.br/conteudo/artigos/tomada-dedecisao-apoiada-o-que-e-e-qual-sua-utilidade/16608\#_ftn2>. Acesso em: 20 jun. 2017. 
SOUZA, Iara Antunes de. Estatuto da Pessoa com Deficiência: Curatela e Saúde Mental. Belo Horizonte: D’Plácido Editora, 2016.

STOLZE, Pablo. É o fim da interdição?. Revista Jus Navigandi, Teresina, ano 21, n. 4605, 9 fev. 2016. Disponível em: <https://jus.com.br/artigos/46409>. Acesso em 1º jul. 2017.

TARTUCE, Flávio. Alterações do Código Civil pela lei 13.146/2015 (Estatuto da Pessoa com Deficiência). Repercussões para o Direito de Família e Confrontações com o Novo CPC. Parte I. Migalhas, 2015a. Disponível em: <http://www.migalhas.com.br/FamiliaeSucessoes/104,MI224217,21048-

Alteracoes+do+Codigo+Civil+pela+lei+131462015+Estatuto+da+Pessoa+com>. Acesso em: 02 jul. 2017.

Alterações do Código Civil pela lei 13.146/2015 (Estatuto da Pessoa com Deficiência). Repercussões para o Direito de Família e Confrontações com o Novo CPC. Parte II. Migalhas, 2015b. Disponível em: <http://www.migalhas.com.br/FamiliaeSucessoes/104,MI225871,51045Alteracoes+do+Codigo+Civil+pela+lei+131462015+Estatuto+da+Pessoa+com>. Acesso em: 02 jul. 2017.

TEIXEIRA, Ana Carolina Brochado; RODRIGUES, Renata de Lima. $O$ direito das famílias entre a norma e a realidade. São Paulo: Atlas, 2010.

VIEIRA, Patrícia Ruy. A interdição civil no direito brasileiro. Revista dos Tribunais, São Paulo, v. 93, n. 826. p. 93-116, ago. 2004.

Recebido em: 23/10/2017 Aceito em: 14/12/2017 
